\title{
PARANGOLÉS E BÓLIDES CAIXAS: O DEBATE ENTRE A INSTITUCIONALIZAÇÃO DA ARTE, O PROJETO ESTETIZANTE NO MODERNISMO NACIONAL E O MOMENTO SÓCIOPOLÍTICOCULTURAL BRASILEIRO SINTETIZADOS NA OBRA DE HÉLIO OITICICA.
}

\section{Carla Benassi}

Mestranda do Programa de Pós-graduação em Arte e Cultura

Contemporânea - UERJ.

O trabalho artístico de Hélio Oiticica é considerado, pelo próprio artista, como Programas in Progress. Neste percurso que articula profundamente pensamento e práxis, temos como marca o enfrentamento plástico com idéias e questões que compreendem um amplo arco que começa na experiência visual pura Metaesquemas, passa pela superação do quadro e da pintura nos Bilaterais e questiona o circuito artístico com suas obras, que não se destinam a serem expostas nos espaços internos dos museus ou consumidas como "mercadorias simbólicas", como nos Programas Parangolés e Bólide Caixa.

\section{Como escreveu o artista:}

DESMISTIFICAÇÃO DO PARANGOLÉ:

Programa do circunstancial $<<$ objeto-event $>>$ aberto não-mitificado

não- teatro

não-ritual

não-objeto d'arte

não-mito

$$
\begin{aligned}
& \text { o q restou do PARANGOLÉ primeiro } \\
& \text { foram as situações circunstanciais }
\end{aligned}
$$
encontros - events de experimentalidade aberta sem aspirações a mito ou ritualidade do momento

amomento amamentar o momento: não elevá-lo a categorias de mito ou 
de preciosidade estética.

Parangolé Síntese

New York, 26 de julho - 26 de dezembro 1972

Parte da obra de Hélio Oiticica nos formatos plásticos e de texto dedicou-se a pensar as relações entre o programa político cultural brasileiro da época e seus interesses ideológicos envolvidos com a implementação de uma identidade cultural brasileira, via o projeto estetizante do modernismo. Oiticica abandona o concretismo e o acusa de ser arte "departamentalizada" comprometida apenas com o projeto de institucionalização modernista, cego ao que tínhamos de cultural mais autêntico.

Em cada um de seus momentos experimentais - dentro da chave que ele identifica como Programas in Progress - podemos observar apuro estético e experimentação de poéticas e materiais que emergem de sua base teórica crítica e reflexiva, tanto quanto da cultura popular. Ao mesmo tempo, sua produção plástica se aproxima visualmente de uma dialética com as imagens da imprensa, como no caso do Bólide Caixa 18, Cara de Cavalo e com as práticas culturais de contextos culturais diferenciadores, como no caso de seus Parangolés. Artista de ampla atuação, Hélio Oiticica criticou com suas experimentações, obras e depoimentos, o então processo de implementação cultural modernista como o vetor modelo de uma identidade cultural brasileira, mais alinhada aos modelos culturais exógenos que aos endógenos de nossa particularidade cultural. Como parte desta crítica, Hélio Oiticica pensou o processo de institucionalização da arte brasileira, que, na sua opinião, era um processo conservador e de diluição, ao qual chamava de "convi-conivência".

Ainda que não se possa pensar a obra de Hélio Oiticica, restrita ao seu foco sóciopolíticocultural e de resgate e valorização de nossas manifestações culturais populares, podemos enfatizar que no caso das construções verbos-visuais Parangolés e de alguns dos Bólides Caixas, o foco do artista tendeu a permanecer sobre estas instâncias ao mesmo tempo em que articulava a vanguarda internacional dos anos $60 \mathrm{com}$ a cultura popular brasileira. Através do poder de suas imagens, de seus textos e de suas experimentações sobre práticas culturais diversas, Hélio Oiticica partia ao encontro de críticas visuais potentes.

Nos Parangolés estão inscritos e escritos parte de seu pensamento crítico sobre o processo de exclusão social no qual se construiu o Brasil, 
onde também se configuram proposições comportamentais e experiências corporais que alinhavam-se aos movimentos de contracultura dos anos 60 . É o próprio artista, que em um de seus textos anuncia:

O QUE IMPORTA: a criação de uma linguagem: o destino de modernidade no Brasil pede a criação desta linguagem, as relações, deglutições, toda a fenomenologia desse processo (com inclusive, as outras linguagens internacionais), pede e exige (sob pena de se consumir num academicismo conservador, não o faça) essa linguagem: o conceitual deveria submeter-se ao fenômeno vivo: o deboche ao <sério>: quem ousará enfrentar o surrealismo brasileiro?

Quem sou eu pra determinar qual ou como será essa linguagem? ou será um nada (conservaçãodiluição)? Sei lá. A diluição está aí - a convi-conivência (doença típica brasileira) parece consumir a maior aporte das idéias - idéias? frágeis perecíveis, aspirações ou idéias? assumir uma posição crítica: a aspirina ou a cura?

Ou a curra: ao paternalismo, a inibição, a culpa.

Texto BRAZIL DIARRÉIA publicado em Arte Brasileira Hoje, Rio de Janeiro, 1973.

Como Celso Favaretto sustenta, Hélio Oiticica instaura e inscreve seu projeto de vanguarda como diferenciador e distanciador dos projetos estetizantes modernistas para o Brasil. Ao fazê-lo, vincula uma proposta plástica brasileira particular, ousada, provocativa, estratégica e antevisora, frente ao contexto internacional segundo questões estéticas, transculturais e sóciopolíticas de nossa brasilidade.

Dadas estas linhas de força que integram e constituem a produção de Hélio Oiticica, serão propostas articulações ligadas a conceitos como contracultura e o processo cultural de institucionalização da arte. Sobre Parangolés Capas e Bólide Caixa 18 Cara de Cavalo, serão abordados os seus possíveis sentidos estéticos e críticos ainda atuais, sobretudo com relação ao processo de institucionalização da arte brasileira em específico e sobre o sentido e o papel político da arte em geral. $O$ texto e a apresentação tomaram como base os livros de Celso Favaretto, o catálogo do Centro de Arte Hélio Oiticica e o livro Aspiro ao Grande Labirinto coletânea de textos de Hélio Oiticica organizados por Lygia Clark e Waly Salomão.

Nos Parangolés Capas e no Bólide Caixa 18, Cara de Cavalo, podemos observar um apuro estético e profundamente experimental de poéticas que se mostram mais alinhadas a uma crítica tanto política, no que tange o contexto político e cultural da época, quanto institucional.

\section{Parangolés}

Parangolés são um conjunto de Programas in Progress formado por Capas, Bandeiras e Proclamação do Parangolé. Estes se configuram mais como 
objetos experimentais de evolução e de exibição pública, do que objeto de fruição artística reservada a museus e galerias. Os mais conhecidos Parangolés são os PCs ou Parangolés Capas, obras-vestimenta e de exposição-evolução que se dava fora do ambiente institucional dos museus. Estas Obras Manifesto apresentavam questões políticas através do poder de suas imagens e de suas narrativas. Aproximavam e articulavam, enquanto experimentações plásticas, práticas culturais diversas de nossa brasilidade mestiçada. Estas obras incluíam também, em sua produção, interesse sobre o processo de exclusão social sobre o qual se construiu o Brasil. Frases como: Da adversidade vivemos, Seja herói seja marginal e Estou com fome, eram divulgadas nos Parangolés Capas por Mosquito, Nildo, Miro e Jerônimo da Mangueira.

Ainda que não se possa pensar a obra de Hélio restrita ao seu foco político, podemos enfatizar que no caso de suas construções verbos-visuais, os Parangolés tendem a permanecer sobre as instâncias políticas e culturais articulando vanguarda, cultura popular brasileira e o radicalismo comportamental dos anos 60 junto à realidade brasileira.

O programa que começa com Parangolés é, nas palavras do artista, “(...) para dar mão forte ás manifestações de inconformismo social (...)" desde as organizadas em um sentido para o artista de revolução e de revirão, sobre determinismos sociais excludentes, ao valorizar a cultura carnavalesca das favelas, sua arquitetura precária no entanto inventiva durável e simbólica, da construção dos barracos do Morro da Mangueira. Quanto á entrada de crítica e institucional, esta se deu, no sentido de "libertar a arte" de sua condição hermética estetizante e elitista que postulava arte, como a criação de objetos de finalidade comercial e de exposição apenas em espaço sacralizado e cultuado como galerias e museus. Antes, Hélio acreditava na arte, como lugar de re-significação quando se articula ao campo cultural local. Em entrevista a Ivan Cardoso em 1979, Hélio Oiticica diz:

(...) Não existe idéia separada do objeto, nunca existiu, o que existe é a invenção. Não há mais possibilidade de existir estilo ou a possibilidade de existir uma forma de expressão unilateral como a pintura, a escultura departamentalizada. Só existe o grande mundo da invenção.

Este permanente estado de invenção, ao qual o artista se refere, nos remete ás suas estratégias comunicacionais, semânticas e verbo-visuais que constroem a sua particular linguagem. O que se desenha no horizonte deste artista, remete a funções múltiplas e não se fecha dentro de uma 
linguagem única. Nesta fase pós-concretista dos Parangolés, encontramos pontos de convergência do plástico, do verbal, do musical e do movimento. É o momento da passagem do estatuto da arte como valor mercadológico, pedagógico, estetizante e elitizante, para o do vivencial e do interativo, da transformação de valores artísticos em sociais e início do seu percurso plástico de encontro a uma crítica sobre a legitimação e ao consenso de arte. Neste sentido de invenção, parte da produção atual nacional em arte, aproxima-se, atualiza e desdobra a proposta de Hélio Oiticica. Coletivos se voltam para o espaço público para veicular sua arte sem a necessidade de expô-la em museus e galerias.

Atrocidades Maravilhosas, Rés do Chão, Formigueiro, A revolução não será televisionada e outros, têm um mesmo sentido de dessacralização e abertura para o espaço além do institucional, onde a arte pode se manifestar sem a rubrica institucional.

Além da atualização, outro viés é a relação aos movimentos de contracultura dos anos 60. Enquanto linguagem, a contracultura produziu incontáveis dialetos verbais, visuais e gráficos e num sentido de mão-dupla alimentou-se de parte das vanguardas históricas como o futurismo e o dadaísmo. Enquanto conceito, a contracultura era afeita às experiências psicológicas e comportamentais, que também influíram sobre a arte contemporânea dos anos 60. A esta démarche internacional, e na condição de repressão imposta pela ditadura militar no Brasil da época, alinharam-se artistas nacionais de diferentes áreas de atuação em torno de afinidades conceitos e práticas que ficaram conhecidos por tropicalismo. Hélio Oiticica foi pessoa chave dentro desta tendência.

Durante os anos 1960, o programa Tropicália e o texto "Esquema Geral da Nova Objetividade", ambos de Hélio Oiticica, junto á efervescência política e cultural da época, se fecundaram com importantes manifestações como as experimentações teatrais do Teatro Oficina de José Celso, a música do Grupo Baiano de Caetano, Gil, Gal e Bethânia, publicações de Waly Salomão como Nave Louca, e do grupo concretista dos irmãos Campos e de Décio Pignatari em São Paulo. Todas estas manifestações da cena da vanguarda artística ficaram conhecidas como produções "tropicalistas". Apesar das naturais diferenças entre estas manifestações e artistas, o que as torna semelhantes é uma certa devoração oswaldiana, que confrontava a realidade sociopolítica da época. A esse momento de reação consciente das transformações políticas pelas quais o Brasil passava pós golpe militar, somaram-se o sentido de crítica e 
experimentalismo que visava não só o político, mas o comportamental e o participativo na perspectiva do artista e do público.

Da circulação de idéias e posturas de atuação dentro destes diferentes grupos, podemos encontrar uma ênfase no princípio da "arte participante" em oposição ao de "arte alienante", e o de "crítica social" ao de "fruição estética".

Dentro deste ambiente efervescente, estas experimentações artísticas nacionais convergiam ao mesmo tempo que também dialogavam com atitudes e tendências similares em arte, como a Body art, a Arte Povera, a Arte Conceitual e - em seu sentido de acontecimento no tempo e no espaço, como algo que não se retêm e por isso não se consome como mercadoria arte - aos happenings praticados pelo grupo estadunidense Fluxus.

\section{Bólide Caixa 18}

Para além das vanguardas de contracultura e do projeto político cultural brasileiro que Hélio Oiticica entendia como de convi-conivência, um outro nível de leitura pode ser desdobrado do Bólide-Caixa 18 (1966), "Homenagem a Cara de Cavalo". Esta obra nos remete a ilustrações, narrativas e iconografias que submetem a imagem da crônica policial ao discurso crítico do autor. É o momento do reencontro da forma com o discurso textual. Sobre o Bólide-Caixa 18 diz Oiticica:

Gostaria de explicar a outra caixa com fotografias e palavras: não é um poema mas uma espécie de imagem-poema-homenagem (isto me faz lembrar Milton Lycidas, quando homenageou um amigo que morreu no mar) a Cara de Cavalo (o morto em cada uma das fotos). Afora qualquer simpatia subjetiva pela pessoa em si mesma, este trabalho representou para mim um "momento ético" que se refletiu poderosamente em tudo que fiz depois: revelou para mim mais um "momento ético" que se refletiu poderosamente em tudo que fiz depois: revelou para mim mais um problema ético do que qualquer coisa relacionada com estética. Eu quis aqui homenagear o que penso que seja a revolta individual social: a dos chamados marginais. Tal idéia é muito prigosa mas algo necessário para mim: existe um contraste, um aspecto ambivalente no comportamento do homem marginalizado: ao lado de uma grande sensibilidade está um comportamento violento e muitas vezes, em geral, o crime é uma busca desesperada de felicidade. Conheci Cara de Cavalo pessoalmente e posso dizer que era meu amigo, mas para a sociedade ele era um inimigo público número um , procurado por crimes audaciosos e assaltos o que me deixava perplexo era o contraste entre o que eu conhecia dele como amigo, alguém com quem eu conversava no contexto cotidiano tal como fazemos com qualquer pessoa, e a imagem feita pela sociedade, ou a maneira como seu comportamento atuava na sociedade e em todo mundo mais. Você nunca pode pressupor o que será a "atuação" de uma pessoa na vida social: existe uma diferença de níveis entre sua maneira de ser consigo mesmo e a maneira como age como ser social. Todos estes sentimentos paradoxais tiveram grande impacto em mim. Esta homenagem é uma atitude anárquica contar todos os tipos de forças armadas: polícia exército etc. Eu faço poemas-protestos (em Capas e Caixas) que tem mais um sentido social, mas este para Cara de Cavalo reflete um importante momento 
ético, decisivo para mim, pois que reflete uma revolta individual contra cada tipo de um condicionamento social. Em outras palavras: violência é justificada como sentido de revolta, mas nunca como o de opressão.

O mecanismo disparado por Hélio implica na perda da legitimidade do discurso sensacionalista da coluna policial, até o seu desmonte e destruição. A erosão de parte do material da crônica policial e a sua dessacralização acontecem para surgir a crítica e as informações que Hélio intenciona passar.

A obra se afirma pela visualidade da imagem, mas se nega pelo discurso do texto que choca e paralisa a cognição já iniciada. A evidência visual, marginal exemplarmente punido pela lei, é cancelada pelo contexto em que se insere, ou seja, dentro do museu. Ao invés de se revelar como pacífica e anódina obra de fruição estética, o Bólide Caixa Cara de Cavalo é protesto que se inscreve dentro do museu.

Bólide Caixa Cara de Cavalo soçobra com a autoridade do discurso jornalístico, que é o de estigmatizar Cara de Cavalo como naturalmente violento e portanto morto exemplarmente, dado a usa conduta nociva ao social. Hélio, por outro lado, nos apresenta um outro lado do personagem, um homem que se revoltou com sua condição e assumiu os riscos de um comportamento desviante e de inconformismo. Peça artística e de protesto, é uma polissemia construtiva que é bem própria da obra de Hélio Oiticica, transitando entre a contradição e a desestabilização dos sentidos e dos valores institucionais.

O Bólide Caixa Cara de Cavalo, além de utilizar operações antiarte duchampianas e dadaístas, aposta também na discursividade e acrescenta as estratégias da metacrítica e da metalinguagem. Visual e verbal urdem nesta obra um momento da transformação de valor e espaço artístico em valor e espaço de critica social. Tal obra não se inscreve banalmente na cadeia sem fim da estetização da arte, porém se estabelece como uma verdade manifesta, como um disjuntor em um lugar especifico que interrompe a corrente de informação dos sistemas discursivos de poder, reproduzidos pela mídia jornal e em relação ao estatuto consensual do que é arte, do discurso elitista e estetizante dos museus.

\section{Considerações Finais}

Ao escolher abordar parte da obra e do pensamento de Hélio Oiticica segundo sua inserção crítica, tentei aqui detectar as variantes possíveis e 
inter-relacionadas entre sua obra e pensamento comparadas ao panorama sóciopolíticocultural nacional e ao cultural internacional, sem a pretensão de ter esgotado o tema. O texto visou ser um exercício a contemplar as possíveis leituras para as quais se abrem a obra e o pensamento de Hélio Oiticica. O texto não teve também por intenção, buscar ou afirmar que em dados momentos, condições e proporções, fatos e contextos políticos específicos afirmam e determinam manifestações artísticas e culturais. Isto me parece ser um caminho reducionista, mas ao mesmo tempo, parte do percurso e da obra de Hélio Oiticica, não devemos deixar de notar, é fenômeno visível de crítica institucional e política que só aos mais incautos poderia escapar. Um dos princípios modernistas, o princípio historicista, foi abandonado por Hélio e a partir desta tomada de posição, suas opções passaram cada vez mais a se dar na direção dos Programas in Progress em sentido autoral e de desvio dos percursos artísticos institucionais e institucionalizantes. Em vez de se fechar sobre o discurso formalista-purista do processo de institucionalização da arte pelo Estado brasileiro da época, ou se acanhar frente ao legado cultural internacional, Helio Oiticica colocou-se de frente com sua realidade e ao mesmo tempo refletiu sobre arte, cultura, política e contexto da ditadura, especialmente no Rio de Janeiro. Suas idéias e produções serviram-se de fontes filosóficas, literárias como a escrita fragmentária de Joyce, do seus anos de convívio nos terreiros da Mangueira, das crônicas jornalísticas, do discurso embolorado do pragmatismo e do formalismo em arte. De fato a personalidade e a obra de Hélio Oiticica contém o mesmo élan e heroísmo que marcaram os movimentos de contracultura dos anos 60. Como assinala Mário Pedrosa, tanto Hélio Oiticica quanto Ligya Clark, anteciparam questões de movimentos posteriores como a $O p$ e a $P p p$ Art internacionais. Segundo o mesmo autor, se necessitarmos traçar alguma genealogia para a obra que não àquela que remete ao próprio Hélio, esta sem dúvida seria o fato dele ser neto de anarquista e portanto, optar por permanecer em estado de invenção e experimentação, onde o componente "crítica política", penso eu, também constou como mais um aditivo do seu Progress.

\section{Bibliografia}

BOURDIEU, Pierre, Livre-Troca: Diálogos entre Arte e Ciência. Bertrand Brasil, 1995. -, Economia das trocas simbólicas, Perspectiva, São Paulo, 2003.

CATÁLOGO do Centro Hélio Oiticica. Rio de janeiro, 1996. 
CHAUÍ, Marilena. Conformismo e Resistência: Aspectos da Cultura Popular no Brasil. São Paulo: Brasiliense, 1986.

COELHO, Teixeira. Dicionário Crítico de Política Cultural: cultura e imaginário. São Paulo: FAPESP, 1997.

FAVARETTO, Celso. A Invenção de Hélio Oiticica. São Paulo: Editora da Universidade de São Paulo, 2000.

FIGUEIREDO, Luciano. Pape, Lygia. Salomão, Waly. Aspiro ao Grande Labirinto. Rio de Janeiro, 1996.

JAPIASSÚ, Hilton e Marcondes, Danilo Dicionário Básico de Filosofia. Rio de Janeiro: Jorge Zahar Ed., 1996.

LECHTE, John. Cinqüenta Pensadores Contemporâneos Essenciais. Rio de Janeiro Difel, 2002.

PEDrosA, Mário. Arte Ambiental, Arte Pós-moderna, Hélio Oiticica. In: Correio da Manhã, 26.06.66 Republicado em Dos Murais de Portinari aos Espaços de Brasilia, pp. 205-209.

PONTUAL, Roberto. Dicionário de Artes Plásticas no Brasil. Rio de Janeiro Civilização Brasileira, 1969.

ZÍLIO, Carlos. Da Antropofagia à Tropicália. In "O nacional e o popular na cultura brasileira - Artes Plásticas e Literatura”. São Paulo, Brasiliense, 1982. 